\title{
Unsteady Flow in Cavitating Turbopumps
}

\author{
J. H. KIM \\ Research Associate, \\ Applied Research Laboratory, \\ The Pennsylvania State University, \\ State College, Pa.

\section{A. J. ACOSTA} \\ Professor, \\ Dept. of Mechanical Engineering, \\ California Institute of Technology, \\ Pagadena, Calif,
}

Unsteady flow in a cawitaiing axial induser pump is analyzed with the holp of a simple two-dimenisional cascade model. Thio proble wn was motivated by a desire to study the effect of unsteady castation on the so-culled POGO instability in the operation of liquid rocket entines. Here, an important fsature is a closed loop coupling between several differthe modes of oseillation, one of which is due to the basic unstady characteristics of the cavilation itself. The approwehing and leaving flow velocities upand downstream of the inducer oscillute, and the cavily-blade system participates dyramically with the basic pulsating flow. In the present work, attention is focused on fivling a transfor matrix that relates the set of upstream variables to thase downsiream. This quantity, inlich is esseniolly equitulent to oavitation cumpliance in the quasistatio analyses, if found to be corroted and frequency dependent. It represents the primary effect of the fluctuating carity in the system. The analysis is based on a linearisod free streamline theory.

\section{Introduction}

The problem of unsteady internat cavitating flows such as frequently observed in a pump or a turbine has drawn renewed attention recently in connection with itw role played in the socalled PUGO instability during the operation of liquid propellart rockets. This kind of system instability typically arlses during the booster stage of flight, and is attributed to a fecdback coupling between the asvitating feed pump, the supponting structure, and the motion of the propellant in the feed linos to the pump. Naturally, because of this rather complituted situation due to the coupling effect, the problerr: has remained somewhat unexplored in its full essence. For instance, although it is generally believed that the unsteady behavion of the cavitation itsolf is of essential importunge to the problem, it is only very recently that an attenipt was unade to incorporate this into the problem $[1,2] .1$

Some of the earlier pioneering works on this subject by Rubin $[3,4]$, Fashbaugh and Streeter [j], and Ghahremani $[6]$ adopted the following typical assumptions in order to make the problem more treatuble:

First, a passive "compliance" is attributed to the presenes of cavitation in the pump, that is, the presence of cavitation $j$ s visualized as acting like a prosurized reservir, and numerical values for the pump osvitation compliance are determined from dynanic experiments, or test etand firings, to make the observed frequencies match the theroetical ones;

Secondly, the behavior of the pump during the unsteady mo-

1Numbers in brackets designate Keferences at ond of paper.

Contributed by the Fluils Fngineering Divigion and presented at the Cavity Flow Syropodium, Minnonpolis, Minn., May 5-7, I075, of Titr Ampricas

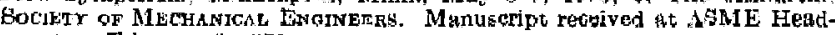
quartert, Fobrutry $5,197 \overline{5}$. tions of the transient flow is assumed to be quasistegdy, namely, the change in putne peiformance parameters with flow rate and inlet prossure is assuned to be the same as that sorresponding to stendy stale operation.

Brenmen and Acosta [7] used this quasisteady line of approach in aulyzing eqvitating oascade. This type of anslysis may be a correct one for a first step, and if the frequencies of oscilation were sufficiently low, the quasisteady representation of the pump performance might prove to be satisfactory. On the other band, it should be pointed out that the inherent unstoudiness of the cavitation is not taken into account in these works, in spite of the fact that this Auctuating behavior of the cavity is an important source of system instability.

The unsteady characteristies of a cavity flow have been considered in a recent stndy by Kin and Acosta [1] using a simple dynamic model of a base-cavitating wedge in a tunnel, and it was concluded that the quasistenty analysis was not adequate for a wide range of frequencies of oscillation. In the present work, we will vreat an unsteady flow througin a cavitating axial inducer pums using the linearized free strearnline theory. The inducor can be represented by a two-dimensional cascade model.

\section{Formulation of the Problem}

Consider a two-dimensional unsteady fow past a eavitating inducer cascade as sketched in Fig. 1. Iret 11 as asurne the cascado blades to be llat plates, semi-infinite in length, with a stager. angle of $\gamma$. The steady angle of in cidence $\alpha$ will be supposed to be small; the cavity is assumed to be slender so that it may be represented as a slit along the vane. The flow is approximated to be incompresible, inviscid, and irrotational. Far upstream, there exists only an axial velodty fluctuation approaching the inducer denoted $b y \tilde{F}_{1} e^{j *}$ and no valgential velocity fuctuation. Far downstrearn, the flow must be parallel to the vanes, and for 
this reasun both the normal or aximl $\left(\bar{N}_{z} e^{i k t}\right)$ and the tangential $\left(\tilde{T}_{2} e^{i(t)}\right.$ ) fluctuations will prevail. It is also ussumed that the whole flow system oscillates at a single frequency $\omega$.

Now, in the absence of the body-cavity system, elementary dynanic principles may be applied to calculate the difference in funtuating pressures between any two remote points in the flow in terms of the pulsating velocity components. The primary effect of inserting the unoteady cavity-blade system (which interferes dynamically with the flow) is then to glter the pressure at these remote points by adilitional amounts $\tilde{P}_{1} e^{j \omega t}$ and $\tilde{P}_{s e}^{j o t}$ respectively for the given velocity disturbances.

Our objective here is to determine these residuary pressures $\tilde{P}_{1}$ and $\widetilde{P}_{2}$ in terms of the fluctuating velodity components for given flow geometry and frequency so that ultimately we may be able to relate the four qualtities $\left(\tilde{F}_{1}, \tilde{P}_{2}\right)$ and $\left(\tilde{N}_{1}, \tilde{N}_{2}\right)$ by

$$
\left(\begin{array}{c}
\tilde{P}_{1} \\
\tilde{P}_{3}
\end{array}\right)=c M\left(\begin{array}{c}
\tilde{N}_{1} \\
\tilde{N}_{3}
\end{array}\right)
$$

where $M$ is a $2 \times 2$ matrix and $c$ is a factor that nondinensionalizco $M . M$ is equipalent to a transfer matrix that relates the upstream conditions to the downstream ones.

The cavity terminus will be assumed fixed. This artificial abumption will make the unsteady and the steady flow probiems separable, and is justiflable only beonuse we are interested in the overall volume fuctuation due to tho cavity and tot in the local behavior of the cavity length variation.

\section{Solution of the Problem}

Let us denote the velocity components in the $x$ - and the $y$ directions oy $U+u$ and $v$, respectively, where $u|/ U| v \mid, / U$ $<<1$.

On the cavity, the linearized Euler's equation in the $x$-direotion gives

$$
\frac{\partial u}{\partial t}+U \frac{\partial u}{\partial x}=0
$$

Writing the perturbation velocity $u=u_{e}+u_{c}(x) e^{j \omega_{t}}$ on the cavity, one finds $u_{c}(x)=g^{-j k a t a}$. Here, $k \equiv \omega d / U$ is reduced frequency and $g$ is a constant $t o$ be determined from the solutive. Along the vanes outside the cavity, $v=0$. The lincarizod $z-$ plane is shown in Fig. 2 with appropriate boundary conditions.

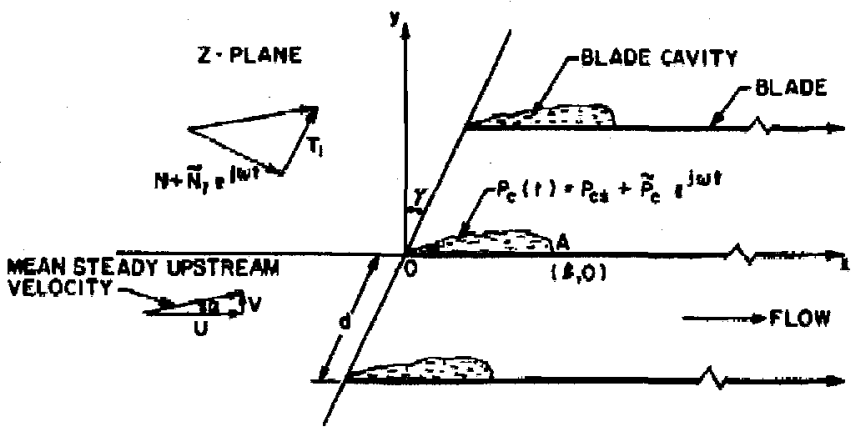

Fig. 1 Sketch of unsteady flow through cavitating cascado

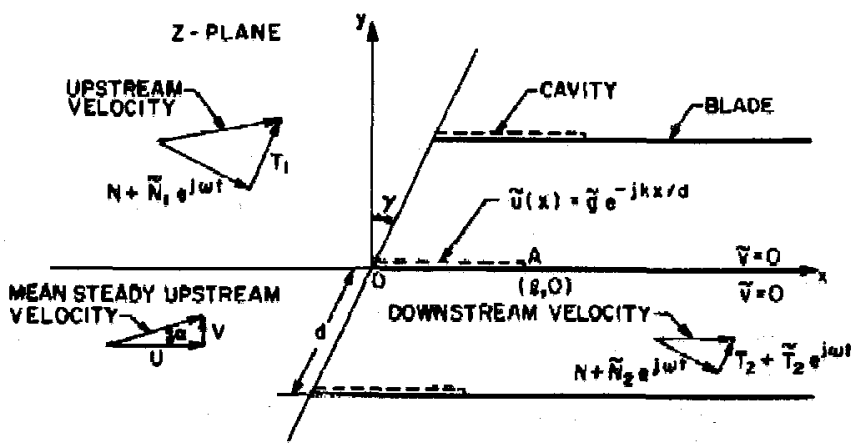

Fig- 2 Linearized zeplane with boundary conditions

The complex perturbation velocity $w=u-i w$ is an analytic function of $: x+i y$ at asch instant by incompressibility ond irlotationality.

To find the solution for $w$, it is convenient to map the linesrized z-plane into the upper half of an auxiliary plane by the following tranfformation $[8,9]$ :

$$
z=\frac{d}{2 \pi}\left[e^{-i \gamma} \ln \left(1-\zeta / \zeta_{1}\right)+e^{i \gamma} \ln \left(1-\zeta / \zeta_{1}\right)\right]
$$

in which the brauch point $\zeta_{1}=\sqrt{ } d e^{i(x / 2-\eta)}$ corresponds to upstrean infinity in the s-plane. Writing $w=w_{*}(\zeta)+w(\zeta) g^{w}$ $d=$ blude spacing along cascade axis

$i=$ unit imaginary number with re. gard to space

$j=$ unit imaginary number with re spect to time, ij $\neq-1$

$k=$ roduced frequency, $\omega d / U$

$l=$ cavity length

$M=$ transfer matrix

$N=$ steady velocity normal to cascade axis

$N_{1}=$ unsteady upstream perturbation velocity normal to caschile

$N_{2}=$ unsteady downstream perturbation velocity normal to cascade

$P_{1}=$ residuary pressure at fir upstreain

$P_{2}=$ residuary pressure at far downstrean

$S=$ abscissa of eavity terminus in the $\zeta$-plane

$T_{1}=$ steady upstrean velocity tan

$-i v)$

gential to coscade axis

$T_{2}=$ steady downstrean velocity tangentia' to cascade axis

$\widetilde{T}_{2}=$ unsteddy downatream perturbation velocity tangential to cascade axis

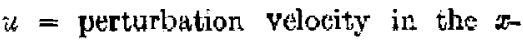
direction

$U=$ steady upstrestn velocity in the $x$ direction

$\tilde{u}=$ unsteady part of perturbation velocity in the $x$-direction

$v=$ perturbation velocity in the $y$ direction

$\tilde{v}=$ unsteudy part of perturbation velocity in the $y$-direction

$w=$ complex perturbation velocity $(w$ $=u=-i v$ )

$\tilde{W}=$ unsteady part of complex perturbation velocity $(\bar{w}=\tilde{u}$ $z=$ complex variable in the physical plane, $z=x+i y$

$\alpha=$ etrady angle of attack at up stresm infinity

$\gamma=$ stagger angle of cascado axis

$\rho=$ fluid density

$\sigma=$ esvitation number

$\omega=$ angular velodity of oscillation

$\zeta=$ complex variable in the transformed plane, $\zeta=\xi+i n$

Subscripts

$1,2=$ conditions at upstream and downstrearn infinity, respectively

c = conditions on the cavity surfice

$\mathrm{s}=$ steady solutions

\section{Superscripts}

$\sim=$ Lnstoudy part 
where $\tilde{w}=\tilde{u}-\tilde{w}$, one con establish the boundary conditions for $\bar{u}$ and $\tilde{v}$ in the $\zeta$-plane as shown in Fig. $\vec{z}$ :

$$
\begin{aligned}
& \bar{y}=0, \xi<0, \eta=0 \\
& \tilde{u}=\tilde{\eta} e^{-i k *(\xi) / d}, 0<\xi<s, \eta=0 \\
& \bar{y}=0, \xi>s, \eta=0
\end{aligned}
$$

where

$$
\begin{aligned}
\frac{z(\xi)}{d}=\frac{1}{\pi}\left\{\frac{\cos \gamma}{2} \ln \right. & \left(1-\frac{\xi}{\sqrt{d}} \sin \gamma+\xi / d\right) \\
& \left.-\sin \gamma \tan -1 \frac{-\xi \cos \gamma}{\sqrt{d}-\xi \sin \gamma}\right\} .
\end{aligned}
$$

The solution of this mixed-type Hilbert boundary value problent is readily found to be $[10,11]$

$$
\begin{array}{r}
\tilde{w}(\zeta)=\frac{\tilde{g}}{\pi \sqrt{\zeta(\zeta-\bar{\zeta})}} \int_{0}^{s} \sqrt{\xi(S-\xi)} e^{-i n x(\xi)(d)} \frac{d \xi}{\xi-\zeta} \\
+\frac{A \zeta+B}{\sqrt{\zeta(\zeta-S)}}
\end{array}
$$

Here, $\tilde{g}, A$, and $B$ are constants (real in space, complex in time) to be determined shortly. $S$ is given from equation (B) by substituting $\xi=S$ and $x(\xi)=l$. The following three conditions are available for the determination of $\tilde{g}, A$, ond $B$ :

(i) At upstream infinity, i.e., as $\zeta \rightarrow \zeta_{1}$,

$$
\tilde{w}=\tilde{N}_{1} \cos \gamma+i \tilde{N}_{1} \sin \gamma
$$

Equation (4) then gives

$$
\begin{aligned}
\frac{\tilde{g}}{\pi \sqrt{\zeta\left(\zeta_{1}-\bar{S}\right)}} & \int_{0}^{B} \sqrt{\xi(S-\xi)} e^{-j \pi \#(\xi) l d} \frac{d \xi}{\xi-\zeta} \\
& +\frac{A \zeta_{1}+B}{\sqrt{\zeta_{1}\left(\zeta_{1}-S\right)}}=\bar{N}_{1}(\cos \gamma+i \sin \gamma) .
\end{aligned}
$$

(ii) At downstream infinity, i.e., as i\$| $\rightarrow \infty$, $\tilde{w}=\tilde{N}_{2} \cos \gamma+\tilde{T}_{\mathrm{z}} \sin \gamma+i\left(\tilde{N}_{2} \sin \gamma-\tilde{T}_{2} \cos \gamma\right)$

Equation (4) thus gives

$$
A=N_{2} \cos \gamma+\tilde{T}_{2} \sin \gamma+i\left(\tilde{N}_{2} \sin \gamma-\tilde{T}_{3} \cos \gamma\right) .
$$

(iii) Also at far downstream, the flow should be parallel to the vanes. Therefore

$$
\tilde{N}_{2} \text { sin } \gamma=\tilde{T}_{2} \cos \gamma .
$$

The foregoing three conditions completely doteraine $f, A$, and $B$, and they can be written

$$
\begin{aligned}
& A=\tilde{N}_{2} / \cos \gamma \\
& \tilde{g}=g_{1} \bar{N}_{1}+\theta_{2} \tilde{N}_{2} \\
& B=\sqrt{d}\left(B_{1} \tilde{N}_{1}+B_{2} \bar{N}_{2}\right)
\end{aligned}
$$

where $q_{1}, g_{2}, B_{1}, B_{3}$ are frequency-dependent constants.

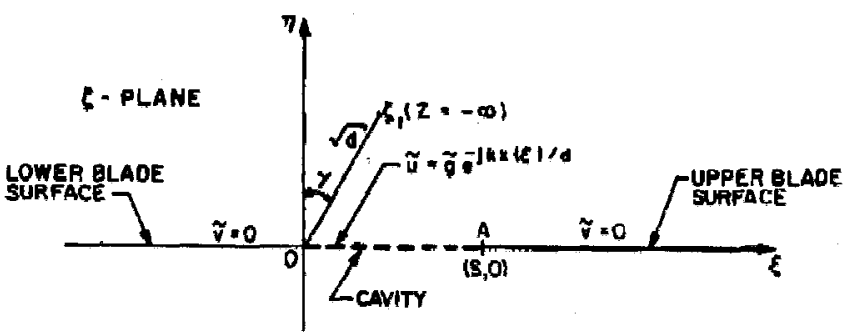

Fig. 3 Transformed plane with linoarized boundary condition:
We now proceed to find the relation between $\left(P_{1}, P_{2}\right)$ and $\left(N_{1}, N_{2}\right)$. As $x \rightarrow-\infty$, the Euler's equation of motion gives

$$
P \rightarrow-j \omega \rho \bar{u}_{1} x^{j} t^{j t}+\tilde{P}_{1} e^{j \omega t}+P_{1}
$$

where $P_{1}$ is the steady mesn pressure at upstream infinity, and $\tilde{\psi}_{1}=\tilde{N}_{1} \cos \gamma$. Tikewige, as $x \rightarrow+\infty$, one may write

$$
P \rightarrow-j \omega \rho \tilde{u}_{2} x e^{* s}+\tilde{P}_{2} e^{i \omega t}+P_{2 s}
$$

where $\tilde{u}_{2}=\tilde{N}_{2} \cos \gamma+\tilde{T}_{y} \sin \gamma$. Also, writing the $x$-velocity by $u_{t}+\tilde{u} e^{j \omega_{t}}$ yields the following linearized equation of motion:

$$
\frac{\partial}{\partial t}\left(u_{r}+u_{\phi} e^{j \omega t}\right)+\frac{\partial}{\partial x}\left(\frac{1}{2} u_{\theta}^{\lambda}+u_{\delta} u e^{j \omega t}\right)=-\frac{1}{\rho} \frac{\partial P}{\partial x} .
$$

Extracting the unsteady part only, one may write

$$
j \omega \tilde{u}+\frac{\partial}{\partial x}\left(u_{0} \tilde{u}\right)=-\frac{1}{\rho} \frac{\partial \tilde{P}}{\partial x} .
$$

Integrating this from $(-\infty, 0)$ to $\left(0^{4}, 0^{4}\right)$, one arrives at

$$
\begin{array}{r}
U\left(\sqrt{1+\sigma} \tilde{g}-\hat{N}_{1} \cos \gamma\right)-j \omega \int_{-\infty}^{0} \frac{d \tilde{u}(x, 0)}{d x} d x \\
=-\frac{1}{\rho}\left(\tilde{P}_{e}-\tilde{P}_{1}\right\rangle
\end{array}
$$

Equation (9) has been applied via the integration by part in the foregoing. Here, $\tilde{P}_{c}$ is the oscillatory pressure on the cavity and $\sigma$ is the oavitation number defined by

$$
\sigma=\frac{P_{1,}-P_{a t}}{1 / s \rho U^{2}}
$$

where $P_{\text {of }}$ is the steady mean pressure on the cavity.

Similarly, the upstream infinity and the downstresm infinity can be related by

$$
\begin{gathered}
U\left[(1-\tan \alpha \tan \gamma) \tilde{N}_{2} / \cos \gamma-\tilde{N}_{1} \cos \gamma\right] \\
-j \omega \int_{-\infty}^{0} z \frac{d \tilde{u}(x, 0)}{d x} d x-j \omega \int_{0}^{\infty} \pi \frac{d \tilde{u}(x, 0)}{d x} d x \\
=-\frac{1}{\rho}\left(\tilde{P}_{2}-\tilde{P}_{1}\right) .
\end{gathered}
$$

It ean be shown that we may put

$$
\begin{gathered}
\int_{-\infty}^{0} x \frac{d \tilde{u}(x, 0)}{d x} d x=d\left(G_{1} \tilde{N}_{1}+G_{2} \tilde{N}_{3}\right) \\
\int_{0}^{\infty} \frac{d \tilde{u}(x, 0)}{d x} d x=d\left(H_{1} \tilde{N}_{1}+H_{2} \tilde{N}_{3}\right)
\end{gathered}
$$

where $G_{1}, G_{3}, H_{1}$, and $H_{2}$ are frequency-dependent constants. Using equations (8), (14), and (15), we can rewrite equations (11) and (13) in the form

$$
\vec{P}=M \vec{N}+\overrightarrow{P_{0}}
$$

whore

$$
\vec{P}=\frac{1}{\rho U^{\prime}}\left(\begin{array}{c}
\tilde{P}_{1} \\
\bar{P}_{2}
\end{array}\right), \vec{N}=\frac{1}{U}\left(\begin{array}{c}
\tilde{N}_{1} \\
\tilde{N}_{2}
\end{array}\right), \vec{P}_{a}=\frac{\tilde{P}_{a}}{\rho U^{2}}\left(\begin{array}{l}
1 \\
1
\end{array}\right)
$$

and

$$
M=\left[\begin{array}{ll}
M_{11} & M_{12} \\
M_{21} & M_{2 \mathrm{i}}
\end{array}\right]
$$


$-\left[\begin{array}{cc}g_{1} \sqrt{1+\sigma}-\cos \gamma & g_{4} \sqrt{1+\sigma}-j k G_{z} \\ -j k G_{1} & \\ g_{1} \sqrt{1+\sigma}+j k H_{1} & g_{4} \sqrt{1+\sigma}-\frac{1-\tan \alpha \tan \gamma}{\cos \gamma}\end{array}\right]$.

Thus we have obtained the relation between $\left(\tilde{P}_{1}, \tilde{F}_{2}\right)$ and $\left(\tilde{N}_{1}, \tilde{N}_{2}\right)$ The matrix $M$ is a transfer matrix between these two sots of variables. Gome numerical values of $M$ are shown in Table 1 for $\alpha=5 \mathrm{deg}$ and $\gamma=75 \mathrm{dgg}$. The csvitation number $\sigma$ was obtained from strady-state solution.

\section{Specific Example}

As a simple domonstration of how to apply this matrix $M$ to a practical problem, it is interesting to consider an exemplary situation shown in Fig. 4. Here, we have an unstedy cavitating axial inducer pump at the end of a feed pipeline that is connected to a very large reservoir. For simplicity, let us take $P_{0}=0$. Assume $L_{1} / d, L_{2} / d>>1$ where $d$ is the vane spacing of the pump. The pressures on the reservoir surface and the discharge section are given as in the figure. We would like to find the Aluctuating normal velocity components $\left(N_{1}, N_{2}\right)$ in terms of the given pressures.

The Bernouli's equation between the reservoir surface and the point $A$ can be written

$$
\begin{aligned}
P_{00}+P_{0} e^{j \omega t} & +\rho g y_{0} \\
& =P_{A s}+P_{A} e^{j \omega t}+\frac{\rho}{2}\left(N+N_{I} e^{j \omega i}\right)^{2}+\left.\rho \frac{\partial \phi}{\partial t}\right|_{A}
\end{aligned}
$$

Here, $\phi$ is the velocity potential. Writing $\phi=\phi_{s}+\phi e^{j \omega t}$, the unsteady part of the foregoing Bemou'li's equation yields

$$
P_{0}=P_{A}+\rho N N_{1}+j \omega \rho \phi_{A}
$$

$P_{A}$ consists of both the residuary part $P_{1}$ and the inertial part. To separate them out, let us consider the equivalent eascude problem illustrated in Fig. 5 . Here, bince $L_{1}$ is large, we may Approximate by equation (9)

$$
P_{A}(1) \cong j \omega \rho N_{1} \cos \gamma\left(L_{1} / \cos \gamma\right) e^{j+t}+P_{1} e^{j \omega t}+P_{A,}
$$

so that we nay identify

\begin{tabular}{|c|c|c|c|c|}
\hline \multicolumn{5}{|c|}{$l / d=0.01(\sigma=12,275)$} \\
\hline$\$$ & $M_{11}$ & $M_{11}$ & $M_{n}$ & $M_{28}$ \\
\hline $\begin{array}{l}0 \\
0.1 \\
0.5 \\
0.7 \\
1.0\end{array}$ & $\begin{aligned} & 4.308 \times 10^{2} \\
& 4.308 \times 10^{2} \\
&+j\left(1.799 \times 10^{-1}\right) \\
& 4.308 \times 10^{2} \\
&+j\left(8.477 \times 10^{-1}\right) \\
& 4.308 \times 10^{2} \\
&+j(1.260) \\
& 4.308 \times 10^{2} \\
&+j(1.799)\end{aligned}$ & $\begin{array}{l}-5.365 \times 10^{2} \\
-5.365 \times 10^{2} \\
-j\left(1.788 \times 10^{-1}\right) \\
-5.363 \times 10^{2} \\
-j\left(8.940 \times 10^{-1}\right) \\
-5.365 \times 10^{2} \\
-j(1.252) \\
-5.365 \times 10^{2} \\
-j(1.788)\end{array}$ & $\begin{array}{r}4.310 \times 10^{2} \\
4.310 \times 10^{2} \\
+j(5.629) \\
4.310 \times 10^{2} \\
+j(2.314 \times 10) \\
4.310 \times 10^{2} \\
+j(0.940 \times 10) \\
4.309 \times 10^{2} \\
+j(5.629 \times 10)\end{array}$ & $\begin{array}{l}-5.391 \times 10^{7} \\
-5.391 \times 10^{2} \\
-j(7.970) \\
-5.390 \times 10^{2} \\
-j(3.989 \times 10) \\
-5.390 \times 10^{2} \\
-j(5.585 \times 10) \\
-5.389 \times 10^{2} \\
-j(7.970 \times 10)\end{array}$ \\
\hline \multicolumn{5}{|c|}{$l / d=0.1(\sigma=2.137)$} \\
\hline t & $M_{11}$ & $M_{12}$ & $M_{31}$ & $M_{n}$ \\
\hline $\begin{array}{l}0 \\
0.1 \\
0.5 \\
0.7 \\
1.0\end{array}$ & $\begin{array}{r}1.779 \times 10 \\
1.779 \times 10 \\
+j\left(6.080 \times 10^{-2}\right) \\
1.777 \times 10^{-1} \\
+j\left(3.039 \times 10^{-1}\right) \\
1.777 \times 10^{2} \\
+j\left(4.255 \times 10^{-1}\right) \\
1.777 \times 10^{-1} \\
+j\left(6.079 \times 10^{-1}\right)\end{array}$ & $\begin{array}{l}-3.267 \times 10 \\
-3.267 \times 10 \\
-j\left(6.258 \times 10^{-2}\right) \\
-3.265 \times 10^{-1} \\
-j\left(3.128 \times 10^{-1}\right) \\
-3.265 \times 10^{-3} \\
-j\left(4.380 \times 10^{-1}\right) \\
=3.265 \times 10^{-10} \\
-j\left(6.258 \times 10^{-1}\right)\end{array}$ & $\begin{aligned} & 1.805 \times 10 \\
& 1.804 \times 10 \\
&+j(3.170) \\
& 1.787 \times 10 \\
&+j(1.585 \times 10) \\
& 1.771 \times 10 \\
&+j(2.210 \times 10) \\
& 1.737 \times 10 \\
&+j(3.169 \times 10)\end{aligned}$ & $\begin{array}{l}-3.528 \times 10 \\
-3.526 \times 10 \\
-j(8.564) \\
-3.496 \times 10 \\
-j(4.283 \times 10) \\
-3.467 \times 10 \\
-j(5.996 \times 10) \\
-3.406 \times 10 \\
-j(8.565 \times 10)\end{array}$ \\
\hline \multicolumn{5}{|c|}{$l / d=0.5(\sigma=0.559)$} \\
\hline b & $M_{\mathbf{1 1}}$ & $M_{12}$ & $M_{21}$ & $M_{22}$ \\
\hline $\begin{array}{l}0 \\
0.1 \\
0.5 \\
0.7 \\
1.0\end{array}$ & $\begin{aligned} & 1.209 \\
& 1.209 \\
&+ j\left(1.539 \times 10^{-2}\right) \\
& 1.207 \\
&+ j\left(7.702 \times 10^{-2}\right) \\
& 1.204 \\
&+ j\left(1.079 \times 10^{-1}\right) \\
& 1.199 \\
&+ j\left(1.544 \times 10^{-1}\right) \\
&\end{aligned}$ & $\begin{array}{l}-4.575 \\
-4.575 \\
-j\left(1.746 \times 10^{-2}\right) \\
-4.567 \\
-j\left(8.748 \times 10^{-2}\right) \\
-4.560 \\
-j\left(1.227 \times 10^{-1}\right) \\
-4.543 \\
-j\left(1.761 \times 10^{-1}\right)\end{array}$ & $\begin{aligned} & 1.468 \\
& 1.446 \\
&+ j\left(7.381 \times 10^{-1}\right) \\
& 9.188 \times 10^{-1} \\
&+ j(3.687) \\
& 3.906 \times 10^{-1} \\
&+j(5.155) \\
&- 7.345 \times 10^{-1} \\
&+ j(7.348) \\
&\end{aligned}$ & $\begin{array}{l}-7.177 \\
-7.109 \\
-j(1.138 \times 10) \\
-5.465 \\
-j(5.689 \times 10) \\
-3.819 \\
-j(7.962 \times 10) \\
-3.136 \times 10^{-1} \\
-j\left(1.137 \times 10^{2}\right)\end{array}$ \\
\hline \multicolumn{5}{|c|}{$l / d=1.0(\sigma=0.111)$} \\
\hline
\end{tabular}

$$
P_{A}=j \omega \rho L_{\mathrm{I}} N_{\mathrm{I}}+P_{1}
$$

Substituting this into equation (18) results in

Table 1 Numerical values of $M$ for $\alpha=5 \mathrm{deg}, \gamma=75 \mathrm{deg}$ 


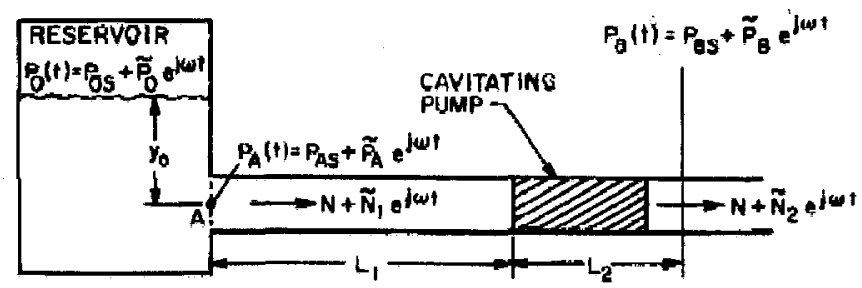

Fig. 4 Exemplary model for cavitating inducer pump in a long channol cobnectod to a Iarge reservoir

$$
P_{1}=P_{0}-\rho N N_{1}-\left(j \omega \rho L_{1} N_{1}+j \omega \rho \phi_{A}\right) .
$$

Defining the "effective" length of the focd line $L_{0}$ by jw $L_{0} N_{1}$ $=j \omega L_{2} N_{1}+j \omega \phi_{A}$, one obtains

$$
P_{1}=P_{0} \rightarrow\left(\rho N+j \omega L_{0} \rho\right) N_{1} .
$$

Similarly, since $L$ is large, may approximate

$$
P_{2} \simeq P_{B}+j \omega p L_{2} N_{3} / \cos ^{2} \gamma \text {. }
$$

Substituting equations (19) and (20) into equation (16) and solving for $N$ and noting that $U=N \cos \alpha / \cos (\alpha+\gamma)$, we finally obtain

$$
N_{1} / N=\frac{P_{0}\left(M_{z}-j \frac{L_{2}}{d \cos ^{2} \gamma}\right)-P_{B} M_{12}}{\rho N^{2} D}
$$

$N_{0} / N=\frac{-P_{0} M_{21}+P_{B}\left(M_{11}+\cos (\alpha+\gamma) / \cos \alpha+j k L_{0} / d\right)}{\rho N^{2} D}$

whoro

$$
\begin{aligned}
D= & {\left[1+\frac{\cos \alpha}{\cos (\alpha+\gamma)}\left(M_{11}+j k L_{q} / d\right)\right]\left[M_{n}\right.} \\
& \left.-j k \frac{L_{2}}{d \cos ^{2} \gamma}\right]-M_{31} M_{21} \frac{\cos \alpha}{\cos (\alpha+\gamma)}
\end{aligned}
$$

Thus $N_{2}$ and $N_{2}$ are completcly determined in terms of known preasures through the matrix $M$. To elucidate the situation

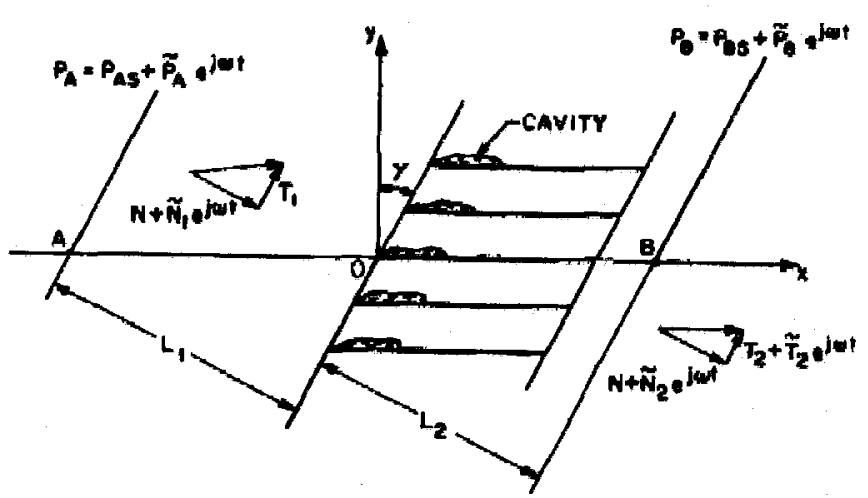

Fig. 5 Equivalont cascade flow for cavitating inducer pump of Fig. 4.

more clearly, let us consider this time a "shug" flow and compare the result thus obtained with those of the foregoing ease. In a slug fow, the whole flow moves in phase, and also we should have $P_{1}=P_{2}$ and $N_{1}=N_{y}=N$, say. In this case, equationa (19) and (20) yield

$$
\frac{\tilde{N}}{N} \pm \frac{\tilde{P}_{0}-\tilde{P}_{y}}{\rho N^{g}}+\frac{1}{\left[1+j k \frac{\cos \alpha}{\cos (\alpha+\gamma)}\left(L_{0} / d+\frac{L_{2}}{d \cos ^{2} \gamma}\right)\right]}
$$

Here, $L_{0}$ is defined by $j \omega L_{0} N=j \omega L_{1} N+j \omega \phi_{A}$. Comparing equation (24) with equations (21) and (22), it is evident that the matrix $M$ ean be thought of as being a measure of the residuary dynamic effect due to the blade-unsteady covity system in addition to the overall genergl oscillation of the flow as a slug.

Numerical values for these two different types of flow are compared in Table 2 for $l / d=0.5$ and $l / d=1.0$. Here, we have taken $\boldsymbol{P}_{B}=0, \boldsymbol{P}_{0}=2$ percent of the stmospheric pressure, $L_{0} / d=50, L_{\sigma} / d=20, \rho=1 \mathrm{gr} / \mathrm{cm}^{2}\left(=1.939 \mathrm{slug} / \mathrm{ft}^{3}\right), N=$ $10.44 \mathrm{~m} / \mathrm{s}(=30 \mathrm{ft} / \mathrm{s}), \alpha \Rightarrow 5 \mathrm{deg}$ and $\gamma=75 \mathrm{deg}$. It is scen

\begin{tabular}{|c|c|c|c|}
\hline \multicolumn{4}{|c|}{$l / d=0.5(\sigma=0.559)$} \\
\hline k & $\overline{N_{1} / N}$ & $N_{3} / N$ & $N / N$ \\
\hline $\begin{array}{l}0 \\
0.1 \\
0.5 \\
0.7 \\
1.0\end{array}$ & $\begin{aligned} & 8.14 \times 10^{-2} \\
- & 1.43 \times 10^{4} \\
+ & j\left(1.77 \times 10^{-3}\right) \\
- & 8.51 \times 10^{-6} \\
+ & j\left(3.76 \times 10^{-6}\right) \\
- & 4.30 \times 10^{-6} \\
+ & j\left(2.69 \times 10^{-4}\right) \\
- & 2.13 \times 10^{-6} \\
+ & j\left(1.88 \times 10^{-1}\right)\end{aligned}$ & $\begin{aligned} & 1.67 \times 10^{-2} \\
& 9.60 \times 10^{-5} \\
&+j\left(1.60 \times 10^{-4}\right) \\
& 2.94 \times 10^{-6} \\
&+j\left(2.05 \times 10^{-5}\right) \\
& 2.85 \times 10^{-7} \\
&+j\left(1.45 \times 10^{-6}\right) \\
&\left.-1.15 \times 10^{-6}\right) \\
&+j\left(1.01 \times 10^{-5}\right)\end{aligned}$ & $\begin{array}{c}2.43 \times 10^{-2} \\
6.77 \times 10^{-5} \\
+j\left(1.88 \times 10^{-8}\right) \\
2.72 \times 10^{-6} \\
+j\left(2.57 \times 10^{-4}\right) \\
1.39 \times 10^{-6} \\
+j\left(1.83 \times 10^{-4}\right) \\
6.79 \times 10^{-7} \\
+j\left(1.28 \times 10^{-4}\right)\end{array}$ \\
\hline \multicolumn{4}{|c|}{$l / d=1.0(0=0.111)$} \\
\hline$\pi$ & $N_{1} / N$ & $N_{2} / N$ & $N / N$ \\
\hline $\begin{array}{l}0 \\
0.1 \\
0.5 \\
0.7 \\
1.0\end{array}$ & $\begin{aligned} & 1.92 \times 10^{-2} \\
& 1.14 \times 10^{-4} \\
+ & j\left(1.85 \times 10^{-3}\right) \\
& 4.19 \times 10^{-6} \\
+ & j\left(3.77 \times 10^{-4}\right) \\
& 2.18 \times 10^{-6} \\
+ & j\left(2.69 \times 10^{-4}\right) \\
1.05 \times 10^{-6} & \\
+ & j\left(1.88 \times 10^{-4}\right)\end{aligned}$ & $\begin{array}{c}1.15 \times 10^{-8} \\
2.34 \times 10^{-4} \\
-j\left(5.19 \times 10^{-1}\right) \\
2.10 \times 10^{-7} \\
-j\left(1.26 \times 10^{-1}\right) \\
-5.70 \times 10^{-6} \\
-j\left(9.05 \times 10^{-6}\right) \\
-8.88 \times 10^{-9} \\
-j\left(6.30 \times 10^{-5}\right)\end{array}$ & $\begin{aligned} & 2.43 \times 10^{-4} \\
& 6.77 \times 10^{-5} \\
&+j\left(1.28 \times 10^{-3}\right) \\
&\left.2.72 \times 10^{-6}\right) \\
&+j\left(2.57 \times 10^{-4}\right) \\
&\left.1.39 \times 10^{-6}\right) \\
&+j\left(1.88 \times 10^{-4}\right) \\
& 6.79 \times 10^{-7} \\
&+j\left(1.28 \times 10^{-4}\right)\end{aligned}$ \\
\hline
\end{tabular}
from these calculations that the values of $N_{1} / N$ and $N_{2} / N$ for the esvitating flow case are appreciably different from those of $N / N$ corresponding to slug flow,

In the presence of ranes but without eavity, we will still have $N_{1}=N_{y}=N$, but in general $P_{1}$ and $P_{2}$ will be relatod by $P_{1}-$ $P_{9}=N N$ tak $\gamma$ through the unsteady Bercoulli's equation. 
In this casc, the quantity inside the brakket of equation (24) will contain an additional term $\tan ^{2} \gamma$.

\section{Concluding Remarks}

In the present formulation, a type of cavitation complianes similar to that of reference [7] will have the form

$$
K^{*}=-\frac{1}{a^{2}} \frac{\partial V^{*} / \partial t}{\partial \sigma^{*} / \partial t},
$$

where $V^{*}$ is the cavity volume per unit depth of the plane and

$$
\sigma^{*}=\frac{P_{1}(t)-\tilde{P}_{r}(t)}{\frac{1}{2} \rho U^{2}}, P_{1}(t)=P_{1}+\tilde{P}_{1} e^{j \omega t}
$$

and $P_{a}(t)=P_{t a}+\tilde{P}_{0} e^{j \omega t}$. This allows us to expreas

$$
K^{*}=-\frac{1}{d^{2}} \frac{d\left(\tilde{N}_{1}-\tilde{N}_{1}\right) e^{j * 1}}{\left.\tilde{P}_{1}-\tilde{P}_{c}\right) e^{j \omega t} / \frac{1}{2} \rho U^{2}}
$$

This may be roarranged in a form

$$
K^{*}=-\frac{\hat{N}_{1} / N-\dot{N}_{1} / N}{2 j k\left(M_{11} \tilde{N}_{1} / N+M_{12} \tilde{N}_{1} / N\right)}
$$

$K$ * thus obtained clearly gives a complex value, that is, the additional dynamic rexponse beyond the purely inertial osdilation of alug flow has both resistive and reactive terms. It aleo shows a strong dependence on frequenty.

Experimental data for onvtation compliance were collected by Vaage, Fidler, and Zehnle [12]. However, these experimental values are by no means direct measurement results, but are inferred from rather complex dynumic models into which experimental observations were substituted. More direct test measurement data are clearly desired in this area.

\section{Acknowledgments}

This work was supported by the National Aeronsutice and Space Administration (Contract NAS 8-28040).

\section{References}

1 Kim, J. H., and Acostin, A. J. "A Note on the Unsteady Cavity Flow in a Tunnel," Juurnal of Fhaids Engindering, Trans. ASME, Mar. 1974.

2 Acosta, A. J., Brennen, C., and Kim, J. H., "Dynamics of Cavitating Cascades," California Institute of Technology, Division of Fngineering and Applied Soience Report No. E184.1, Nov, 1972 .

3 Rubin, S., "Instability Model of Missile Longitudinal Oscillation Due to Propulsion Feedback," Report No. TOR269(4126)-28, Aerospace Corporation, Sept, 1964.

4 Rubiu, S., "Longitudinal Instability of Liquid Rockets Due to Propulsion Feedback (POGO)," Journal of Spaceraft and Rockers, Vul, 3, No. 8, Aug. 1966.

5 Fashbaugh, R. H., and Streeter, V. L., "Resonance in Liquid Rooket Engine Systems," TraNs. ASME, deries D, Vol. 87, No. 4, 1965 .

6 Ghabremani, F, G., "Pump Cavitation Compliance," Cavitation Forum 1971, ASME Publication, 1971.

7 Brennen, Q; and Acosta, A. J., "A Note on Turbopump Cavitation Complianoe for the POGO Instability," 1972 Polyphase Flow Forum (formerly, Cavitation Forum), ASME.

8 Sutherland, C. D., and Cohen, H., "Finito Gavity Cascade Flow," Procedingys of the 3rd U. S. National Congress of Applied Mechanios, 1958, pp. 837-845.

9 Wade, R. B., "Linearized Theory of a Partislly Covitating Cascade of What Plate Hydrofoils," Applied Soientific Resesrch, Vol. 17,1967 .

10 Muskhelishvili. N. I., Bingular Integral Bquations, P. Noordhoff, Limited, Gronigen, Holland, 1946.

11 Cheng, $H$. K, and Rott, N. "Generalization of the Inversion Formula of Thin Airfoil Theory," Journal of Rational Mechanice and Analysis, Indiana University, Vol, 3 , 1954 .

12 Vaage, R. D., Fidler, L. E., and Zehnle, R. A., "Investi- gation of Charaoteristies of Feod System Instabilltios," Interim Report, Martin Marietta Colp., MCR-71-278.

\section{I S C U S \$ I O N}

\section{B. Lakshminarayana²}

The authors are to be commended for the gimple approseh to one of the most difficult and least understood phenomens in fuld machinery. With a viow toward practical application, I would like the authors to clarify some of the assumptions mado.

1 Our experience (based on airflow tests at Penn State and model tests with water by NASA tewis Rowearch Center) indicats that the flow in these inducer passages is highly three dimensional, viscous, and rotational. Substantial pressure and velocity gradients exist in all directions, more so in the radial direction. The eecondary and boundary layer flows dominate orer the "primary" inviscid flow. The steady flow oolculations based on inviscid eascade theories are nowhere near the moasured properties. Can the authors comment on whether their theory holds good under these circumstances or ean we treat the steady flow as viseid and rotational and unsteady part as irrotutional and jnviscid, assuming of course that the unsteady stresses arc small compared to unsteady inertial and pressure forces?

2 The authors assume that the cavity depth is infinitely thin, whereas in actual practice the ratio of cavity depth to blade spacing can be appreciable. It would be useful if the authors could explain, qualitatively, what effect this has ou their transfer matrix.

3 Presence of two-phase modium in the passage (vaporliquid mixture), as well as vapor bubbles are known to cause the instability in the operation of the liquid rocket enginos. The authors have studied the latter effoct. Recent work by Kolesnikov and Kinelev (Izvestia Vuz, Aviatsionnaya tecknitu, Vol. 16, No. 4, 1973, pp. 87-92) indicate that the former effect may be important, since even a slight amount of vapor phase in the flow medium is accompsnied by a marked reduction in specd of sound. The presure and velocity perturbations at the exit are transmitted to the inlet. Can the authors explain which of these two phenomena is more important in the study of instsibility?

4 The outhors assume that the blades are infinitely long. Can the authors explain whother or not the trassfer matrix would depend on the (cavity length/whord length); if so, how? Could this be done by defining the reduced frequency based on chord length (os is done by most of turbomachinery unsteady aerodynamists) instead of blade spaçing?

The authors have provided an important groundwork for future studies on dynamic inducer eavitation behavior. The data from the experimental program underway at Cal Tech should provide the check on the assumptions made in this as well an other theories proposod for the pump instability.

\section{C. S. Songs}

I would like to commend the authors for their work attemptiog to explain the counplieased phenomenon of feed-line cavitatingpump instability. It appears that the use of unsteady cavitating cascude theory is a right approach to partially explain the "compliance" effect of the cavitating pump. Perhaps a combination of unsteady cavity flow theory and the theory of hydraulic transients is neaded to complete the solution.

Following are some of the quostions I believe need clarification.

1. In this model authors gonsidered semi-infinitely loag casoade blades. How realistic is the model in representing the actual pump blades? It is well known that the oxistence of a free yortex wheet behind a foil is a primary factor in determining the unsteady force.

2 In dealing with an unsteady cavity flow problem, previous

JProlaroor of Aeropuace Engingering. The Penneylvonia State Univeraity State College, Pa.

Untrardity of Minnesoth, Minneapolis, Mini. 
invcstigators often used an additional constraint condition, such as the constant cavity volume condition and the cavity elosure condition to render the solution unique. Is such a condition required for this model?

3 Closely related with question 2 are tbe questions of pressure at infinity and the convergence of equations (14) and (15). Did the authors encounter any problem in performing the integrations appearing in these equations? Also, is the pressure at infinity as given by equation (9) bounded at infinity?

4 There is no indication given in the paper as to the method of computing $\tilde{\phi}_{A}$ appearing in equation (18). Is this function bounded at infinity?

5 In the "specific example" authors extonded the potential flow solution to the entrance of the pipe, point $A$ in Fig. 4. In the real case, however, the potential flow is applicable only near the pump. When the feed line $L_{1}$ is very long, as in the case considered by the authors, it appears more realistic to regard the flow in $L_{1}$ as that of one-dimensional transient flow in an elastic pipe. What is the justifoation for the apparent neglect of the transient effect?

\section{Authors' Glosure}

The authors appreciate the important comments of the discussers each of whose own work is well known in the fields of cavitation and turbomachines. As a generyl remark, the present work can only be thought of as a qualitative guide to one aspect of the unsteady cavitating flow in real pumps. We would certainly agree with $\mathrm{Dr}$. Lakshminarayana that viscous effects are important in inducer pumps but insofar as the effects of attached blade cavitaivo are concerned, the main trends of the steady and unsteady flow are not, we believe, dominated by viscosity. As an example of this trend, reasonable estimatos of the "breakdown" cavitation number can be made with inviscid cavity flow cascade andysis. But of course it would be highly desirable to make internal flow measurements in cavitaling inducers and we would hope that this type of observation may eventually becoine available. Apart from this, the methods of analysis are those of fully linearized free streamline theory and the resulting per. formance coefficients are subject to the limitations inherent in this theory. But as reference to the work of Furuya $[13]^{4}$ shows, the linear theory is often a reasonable qualitative guide for steady flow even under conditions where the cavity thickness is not "thin" but the other conditions of the linearization are satisfied. We would expect a similar result for the present unsteady problem.

We appreciate the reference for the Russian literature; we are aware of the possible effects of free stream bubbles and the effect on pump dynamics. Indeed, the recent analyses by $\mathrm{C}$. Brenten [14] suggest that this effect on the cavitation compliance can be significant, and further research in this area may be necessary.

\footnotetext{
TNumbers in brackete desirnate Additional Referensug at end of slosure.
}

Both Drs. Song and Lakshminarayana expreas concern about the infinite solidity of the partially cavitating cascade. The cascade sections of representative inducer punps are often large compared to unity and the additional effects brought about by cavitation in steady flow can often be treated as if this solidity was infinite. The results of such an approximation would seem to provide a useful guide for the preliminary exploration of unsteady effect also. For this to apply to a plausible physical system, it seems reasonuble (lacking of full unalysis) that the reduced frequency based on blade spacing should not be too high. It is not difficult in principle to construct a solution for the finite solidity case (including all trailing vortex wakes) although the details of the analysis become much more tedious. The authors are, however, deeply interested in this "axial gust" problem and hope to present additional results in the near future to clarify this admittedly important effect.

In reply to Dr. Song's second comment, the fluctuating cavity volume is in fact the key element in the problem as it is only this that pernits the up-and downstream normal velocity components to differ. But it is regrettably not very clear from the toxt just what the conditions on the cavity and its termination are; the cavity termination point, $s$ of Fig. 3 , is assumed to remain fixed during the oscillation and the boundary of the cavity moves to provide the net source strength of the fluctuating volume. Other termination models are certainly possible but the present one which is similar to Leehey's [15] was adopted for simplicity.

As to the remaining questions, convergence can be shown of integrals in equations (14) and (15) in a straightforward manner by performing the integrations in the $\zeta$-plane. The total pressure at infinity as given by equation (9) is not bounded and need not be bounded as we allow the oseillation of the flow. However, the residuary pressure there is bounded.

The term $\widetilde{\phi}_{A}$ is to be determined from a separate potential flow analysis of the inflow into the pipe; it is of the order of the reference velocity times a channel height. Finally, in commenting upon the use of the present results we could imagine that the effect of inserting the "pump-caseade" system into any hydraulic network could be accounted for by use of the relations of equation (16). This should be so because these "residual" pressure effects are in effect determined by the flow within a few blade spacings only. Thus, the feed line $L_{1}$ of the example could well have been replaced by an elastic one and the equations governing wave propagation in this pipe would be terminated at the pump site with equation (16). The example of the text was only to show in a simple case how these separate pump and feed line effects could be coupled.

\section{Additlonal Reforences}

13 Furuya "Exact Supercavitating Cascade Theory," Cavity Flows, ASME Symposiun, 1975, p. 19.

14 Brennen, C., Journal of Flums Engineering, Dec. 1973, pp. 533-541.

15 Leehey, P." "Boundary Conditions for Unsteady Supercavitsting Flows," Fourth Symposium on Naval Hydrodynamis, Office of Naval Research, ACR-92, 1962, p. 577. 